\title{
Sleep Quality and Lower Urinary Tract Symptoms Among Patients with Prostatic Diseases
}

\author{
Abimbola Oyelekan, ${ }^{1}$ Olawale Ogunsemi, ${ }^{1}$ Taiwo Afe, ${ }^{1}$ Babatunde Ayoade, ${ }^{1}$ Collins Nwokoro, ${ }^{1}$ Olukayode \\ Oluyemi, ${ }^{1}$ Funmilayo Oyelekan, ${ }^{2}$ Olufunke Adeleye ${ }^{1}$
}

1. Olabisi Onabanjo University College of Medicine

2. Federal Neuropsychiatric Hospital Aro - Nursing Abeokuta, Ogun, Nigeria

Correspondence to: Dr. Abimbola Oyelekan; Email: bimbooyelekan@gmail.com

\begin{abstract}
Background: Incidence of symptomatic prostatic diseases increases with age. Nocturia disturbs sleep. We set out to determine the quality of sleep and severity of lower urinary tract symptoms (LUTS) and bother score in patients with benign prostatic hyperplasia $(\mathrm{BPH})$ and carcinoma of the prostate (CAP). Methods: A crosssectional study of new patients seen in the urology outpatient clinic with bladder outlet obstruction (BOO) from either $\mathrm{BPH}$ or CAP over a period of 18 months. Patients were interviewed using Pittsburgh Sleep Quality Index (PSQI) and International prostate symptoms score (IPSS) questionnaires. Data obtained were analyzed using SPSS version 23. Results: 168 patients were interviewed. CAP patients were older than their BPH counterparts. About $45 \%$ of the patients had poor sleep quality. CAP patients (52.9\%) were more of poor sleepers compared
\end{abstract}

with BPH patients $(40.0 \%)$. CAP patients $(46.3 \%)$ had more severe IPSS than BPH patients (33.3\%). Both CAP (70.6\%) and BPH (76.0\%) patients reported high bother score. Conclusion: CAP and BPH patients have high bother score, affirming need for early treatment. CAP patients had more severe lower urinary tract symptoms and poorer sleep quality than BPH patients.

Keywords: IPSS, Sleep quality, LUTS, Bother score Ann Afr Surg. 2020; 17(2):69-71

DOI: http://dx.doi.org/10.4314/aas.v17i2.6

Conflicts of Interest: None

Funding: None

(C) 2020 Author. This work is licensed under the Creative Commons Attribution 4.0 International License.

\section{Introduction}

Prostatic diseases including carcinoma are major health problems encountered in middle aged and elderly males worldwide $(1,2)$. The diseases are more common in men from the sixth decade of life and beyond as evidenced by their high prevalence of lower urinary tract symptoms (LUTS) (3-5). Fifty percent of men above 50 years of age have benign prostatic hyperplasia (BPH) and this increases to $90 \%$ by 80 years (6). Severity of LUTS can be assessed using the international prostate symptoms score (IPSS), and its bother score component can indicate need for treatment of troublesome urinary symptoms (7). Prostatic disease is associated with poor quality of sleep (8). Sleep in middle aged and the elderly is less restorative and is characterized by frequent awakenings, affecting quality of life (9). Clinicians often trivialize complaints of insomnia during consultations at urology clinics, but significant correlation has been documented between the frequency of nocturia and severity of insomnia $(8,10)$. Sleep and mood disturbances should be recognized in patients during urologic consultations since non-urologic disease may contribute to morbidity and mortality (11).

A number of factors affect sleep quality among patients with lower urinary tract (LUT) obstruction. Sleep problems and LUTS often develop together (12). There is a dearth of studies on sleep quality in different prostatic diseases in this environment. This study therefore set out to compare the quality of sleep, severity and bother score of LUTS in patients with carcinoma of the prostate (CAP) and benign prostatic hyperplasia (BPH).

\section{Methods}

This cross-sectional study was conducted in Olabisi Onabanjo University Teaching Hospital, Sagamu, over 18 months from July 2016 to December 2017. Consecutive consenting new patients with lower urinary tract symptoms and with diagnosis of bladder outlet obstruction (BOO) secondary to either BPH or CAP were recruited into the study after appropriate counselling 
about the purpose and benefits of the study. Patients with urethral stricture and BPH or CAP already on urethral or suprapubic catheter or any other form of treatment at presentation were excluded from the study.

Patients were interviewed using Pittsburgh Sleep Quality Index (PSQI) and International prostate symptoms score (IPSS) questionnaires. PSQI is a self-administered questionnaire for assessing sleep quality in the previous month; it contains 19 self-rated questions generating seven components of sleep assessment: subjective sleep quality, sleep latency, sleep duration, sleep efficiency, sleep disturbance, use of sleep medications and daytime dysfunction. Each component is scored between 0 and 3, yielding a global PSQI score between 0 and 21. High scores indicate lower quality of sleep. A global PSQI score $>5$ indicates that the subject is a poor sleeper (13). It has been used extensively to assess quality of sleep (14). Adopted in 1993 by the World Health Organization (WHO), the IPSS was used to assess severity of lower urinary tract symptoms and its bother score component was used as a single measure of need for treatment (15). A total IPSS score of $0-7,8-19$ and 20-35 signifies mild, moderate and severe symptoms respectively (16).

The obtained data were analyzed using SPSS version 23 . Frequencies and percentages were computed for categorical variables while means and standard deviations of the continuous variables were also determined. Proportions of categorical variables were compared using the Chi-squared test. Pearson's correlations method was used to assess parametric data, and $\mathrm{p}$ value $\leq 0.05$ was considered significant. Ethical approval for the study was obtained from Olabisi Onabanjo University Teaching Hospital Health Research Ethics Committee (OOUTHHREC).

\section{Results}

One hundred and sixty-eight patients were interviewed. Most $(59.5 \%)$ of the patients had BPH, while $40.5 \%$ had CAP. The age range of BPH and CAP patients was 45-89 years and 48-92 years respectively.

CAP patients were significantly older than BPH patients (mean age $71.96 \pm 10.44$ years vs. $65.86 \pm 9.63$ years; $\mathrm{t}=3.893$, $\mathrm{p}=0.000$ ).

The mean Pittsburgh's global score was $4.33 \pm 2.62$ while the scores for CAP and BPH patients were $4.65 \pm 2.36$ and $4.11 \pm 2.78$, respectively $(\mathrm{t}=1.305, \mathrm{p}=0.194)$. Almost half of the patients $(45.2 \%)$ who had prostatic diseases had poor sleep quality. CAP patients $(52.9 \%)$ were poorer sleepers than $\mathrm{BPH}$ patients $(40.0 \%)$, although this was not statistically significant $\left(X^{2}=2.736, p=0.098\right)$.

CAP patients $(46.3 \%)$ had more severe IPSS than BPH patients $(33.3 \%)$. Both CAP (70.6\%) and BPH (76.0\%) patients reported high bother score.

The IPSS severity distribution for CAP patients was $22.4 \%, 31.3 \%$ and $46.3 \%$, while for BPH was $26.9 \%$, $39.8 \%$ and $33.3 \%$ respectively for mild, moderate and severe symptoms. Fisher's exact test showed no significant difference in the severity of prostate symptoms between the two categories.

The overall mean bother score was $4.32 \pm 1.44$. The mean bother scores for CAP and BPH patients were $4.34 \pm 1.46$ and $4.30 \pm 1.44$ respectively, $p=0.035$. Significant correlation was seen between IPSS and the bother score (Table 1).

\begin{tabular}{|c|c|c|c|}
\hline Variables & PSQI & IPSS & Bother score \\
\hline $\begin{array}{l}\text { PSQI } \\
\text { Scores }\end{array}$ & $\mathrm{r}=1.00$ & $\begin{array}{l}\mathrm{r}=0.07 \\
\mathrm{p}=0.38\end{array}$ & $\begin{array}{l}\mathrm{r}=0.09 \\
\mathrm{p}=0.25\end{array}$ \\
\hline $\begin{array}{l}\text { IPSS } \\
\text { Scores }\end{array}$ & $\begin{array}{l}\mathrm{r}=0.07 \\
\mathrm{p}=0.38\end{array}$ & $\mathrm{r}=1.00$ & $\begin{array}{l}r=0.55 \\
p=0.000\end{array}$ \\
\hline $\begin{array}{l}\text { Bother } \\
\text { scores }\end{array}$ & $\begin{array}{l}r=0.09 \\
p=0.25\end{array}$ & $\begin{array}{l}r=0.55 \\
\mathrm{p}=0.000\end{array}$ & $\mathrm{r}=1.00$ \\
\hline
\end{tabular}

There was no significant correlation between total IPSS and PSQI for CAP patients $(\mathrm{r}=0.234, \mathrm{p}=0.198)$ and in the BPH patients $(r=0.104, p=0.488)$. Correlation was not significant between nocturia and PSQI $(\mathrm{r}=0.013$ at $\mathrm{p}=0.87$ ); however, correlation was significant between IPSS and bother score across all the patients.

\section{Discussion}

Our study evaluated and compared sleep quality, severity and bother score of LUTS in BPH and CAP patients. CAP patients were significantly older than BPH patients. This finding is consistent with what was reported in this part of the world $(17,18)$. This is expected as CAP prevalence continues to increase with advancing age $(19,20)$. The youngest patient with CAP was 48 years, and mean age was similar to findings by Eke et al. (21) where only $2 \%$ of their patients were below 50 years and mean age was 71.6 years.

In our study, there was no statistical significance between the mean PSQI scores of patients with CAP and BPH. However, our finding of global PSQI score of 4.33 was much lower than 8.76 reported by Araujo et al. on 50 
CAP patients on hormonal therapy prior to or after radical prostatectomy with radiotherapy or radiotherapy alone done in Brazil (22). This higher value in their study may be due to the selection of participants on hormonal therapy compared with participants in our study who were not on prior treatment or hormonal medication. We would expect that patients who are on treatment for chronic diseases should have better quality of sleep than those not on treatments. However, the higher PSQI score observed by Araujo et al. may be explained by the side effects of hormonal therapy which causes excessive night sweating, which has been documented to adversely affect the quality of sleep (23).

Close to half $(45.2 \%)$ of our patients had poor sleep quality, this is higher than what was reported in a general population study (24). Furthermore, CAP patients had higher frequency of poor sleepers than BPH patients, even though it was not statistically significant. This corroborates our findings on CAP patients having more of severe LUTS on IPSS than BPH patients, and moderate to severe IPSS in CAP patients than in BPH patients. This is higher than the finding of moderate to severe symptoms in $50 \%$ of men with histologically confirmed BPH (25). In addition, CAP patients tend to bother more about their condition than BPH patients, as observed on the IPSS bother score. The significant correlation between IPSS and bother score across all the patients reaffirms need for treatment.

Findings from this study will bring to the fore the sleep quality in pre-treatment prostatic diseases which hopefully can be continued later to see the effect of hormonal deprivation and other treatment modalities. Generalization of this study is hindered by the sample size.

\section{Conclusion}

The finding of high bother score in this study reaffirms the need for early and adequate treatment of BPH and CAP patients to prevent morbidity and improve quality of sleep.

\section{References}

1. Farrell J, Petrovics G, McLeod DG, et al. Genetic and molecular differences in prostate carcinogenesis between African American and Caucasian American men. Int J Mol Sci. 2013; 14(8):15510 31 .

2. Sausville J, Naslund M. Benign prostatic hyperplasia and prostate cancer: An overview for primary care physicians. Int J Clin Pract. 2010; 64(13):1740-5.

3. Olapade-Olaopa E, Owoaje E, Ladipo M, et al. Frequency and pattern of lower urinary tract symptoms in a screened population of men above 40 years in Ibadan, southwestern Nigeria. J West Afr Coll Surg. 2015; 5(4):60.

4. Lepor H. Pathophysiology, epidemiology, and natural history of benign prostatic hyperplasia. Rev Urol. 2004; 6(Suppl 9):S3-10.

5. Osegbe D. Prostate cancer in Nigerians: Facts and nonfacts. J Urol. 1997; 157(4):1340-3.

6. Oesterling J. Benign prostatic hyperplasia: a review of its histogenesis and natural history. Prostate Suppl. 1996;6:67-73.

7. Barry M. Evaluation of symptoms and quality of life in men with benign prostatic hyperplasia. Urology. 2001; 58(6):25-32.

8. Katz D, McHorney C. Clinical correlates of insomnia in patients with chronic illness. Arch Intern Med. 1998;158(10):1099-107.

9. Schneider T, Stanley N. Impact of nocturia on sleep and energy. Eur Urol Suppl. 2007; 6(9):585-93.

10. Chartier-Kastler E, Leger D, Montauban V, et al. Impact of nocturia on sleep efficiency in patients with benign prostatic hypertrophy. Prog Urol. 2009; 19(5):333-40.

11. Walia A, Lomeli L, Jiang P, et al. Patients presenting to a men's health clinic are at higher risk for depression, insomnia, and sleep apnea. Int J Impot Res. 2019; 31(1):39-45.

12. Branche B, Howard L, Moreira D, et al. Sleep problems are associated with development and progression of lower urinary tract symptoms: Results from REDUCE. J Urol. 2018; 199(2):536-42.

13. Buysse D, Reynolds III C, Monk T, et al. The Pittsburgh Sleep Quality Index: A new instrument for psychiatric practice and research. Psychiatry Res. 1989; 28(2):193-213.

14. Ogunsemi O, Bodunde O, Afe T, et al. Quality of sleep and psychological distress in glaucoma. Annals of Health Res. 2016; 2(1):24-30.

15. O'Leary M. Validity of the "Bother Score" in the evaluation and treatment of symptomatic benign prostatic hyperplasia. Rev Urol. 2005; 7(1):1-10.

16. Özcan A, Özdil K, Kaya Ş. The correlation between symptoms of benign prostatic hyperplasia and the quality of life: A field study. Int J Urol Nurs. 2019; 13(1):31-8.

17. Udoh E, Ukpong A. Causes of bladder outlet obstruction in adult males, relative frequency and mean age at diagnosis. SAS J Surg. 2016; 2(4):156-60.

18. Ogunlewe J, Osegbe D. Zinc and cadmium concentrations in indigenous blacks with normal, hypertrophic, and malignant prostate. Cancer. 1989; 63(7):1388-92.

19. Ballentine C, Coffey D. The prostate: An increasing medical problem. The Prostate. 1990; 16(1):39-48.

20. Salinas C, Tsodikov A, Ishak-Howard M, et al. Prostate cancer in young men: An important clinical entity. Nat RevUrol. 2014; 11(6):317-23.

21. Eke N, Sapira M. Prostate cancer in Port Harcourt, Nigeria: Features and outcome. Nig J Surgical Res. 2002; 4(1):34-44.

22. Araújo I, Barbosa M, Barichello E. Sleep disorders in men with prostate cancer undergoing hormone therapy. Escola Anna Nery. 2014; 18(4):705-9.

23. Savard J, Ivers H, Savard M, et al. Cancer treatments and their side effects are associated with aggravation of insomnia: Results of a longitudinal study. Cancer. 2015; 121(10):1703-11.

24. Asghari A, Farhadi M, Kamrava S, et al. Subjective sleep quality in urban population. Arch Iran Med. 2012; 15(2):95-8.

25. Roehrborn C. Etiology, pathophysiology, epidemiology and natural history of benign prostatic hyperplasia. Campbell's Urology. 2002:1297-330. 